\title{
Growth hormone therapy in non-islet cell tumor mediated hypoglycemia associated with metastatic lung adenocarcinoma
}

\author{
Cannavo $\mathrm{A}^{1}$, San Martin $\mathrm{VT}^{2}$, Ali $\mathrm{KF}^{2}$ and Makin $\mathrm{V}^{2}$ \\ ${ }^{1}$ The Medicine Institute, Cleveland Clinic, Cleveland, OH, USA \\ ${ }^{2}$ Endocrinology and Metabolism Institute, Cleveland Clinic, Cleveland, OH, USA
}

\begin{abstract}
Severe hypoglycemia is a rare but serious sequela of malignancy. It may be seen with either islet or non-islet cell tumors. Treatment of non-islet cell tumor mediated hypoglycemia (NICTH) is often challenging, especially when rapid tumor debulking is not feasible. Medical therapies with glucocorticoids and enteral feeds have been utilized in the past, but with limited success. The use of recombinant human growth hormone (rhGH) in cases of NICTH, although seemingly effective, has been limited to end-stage cancers, due to its potential for accelerating tumor growth. Here, we report the successful use of rhGH in severe and refractory NICTH, in a patient with non-operable metastatic lung adenocarcinoma, without altering the patient's oncological outcome.
\end{abstract}

\section{Introduction}

Severe hypoglycemia is a rare but serious sequela of malignancy [1]. It can be seen with both islet and non-islet cell tumors. In regards to non-islet cell tumor hypoglycemia (NICTH), no single pathogenic mechanism explains all cases of this paraneoplastic phenomenon. It is thought, however, that the majority of cases occur as a result of tumor production of molecules with insulin-like activity which in turn stimulate insulin receptors. An incompletely processed insulin-like growth factor 2 (IGF-2), known as "big" IGF-2, has been implicated in the majority of the reports found in the medical literature [1].

Tumor debulking, through surgical and/or medical oncologic treatments, is the mainstay therapy for NICTH [2]. When rapid debulking is not feasible, medical therapies such as glucocorticoids and recombinant human growth hormone (rhGH) have been utilized to ameliorate the hypoglycemic episodes [3]. Unlike glucocorticoids, experts recommend limiting the use of rhGH within the realm of palliation, in end-stage cancers, due to its potential for accelerating tumor growth. Few case reports have been published on the use of rhGH in NICTH, the majority of which have been reported in palliative care settings [4,5]. Herein, we report the successful use of rhGH, outside of the conventional palliation window, in treating severe and refractory NICTH, without altering the patient's oncological outcome.

\section{Case presentation}

A previously healthy 78-year-old man with no previous chronic conditions was diagnosed with non-operable lung adenocarcinoma with metastases to the brain and spine. Factoring in his pre-treatment ECOG (Eastern Cooperative Oncology Group) performance status of 1 , he had a projected life expectancy of approximately 3 years. Shortly after his cancer diagnosis, and prior to starting therapy with Afatinib (Gilotrif), he reported several episodes of diaphoresis and blurry vision, particularly after prolonged fasting states. During these episodes, he was documented to have blood glucose (BG) measurements in the range of $25-30 \mathrm{mg} / \mathrm{dL}$ (normal range: $65-100 \mathrm{mg} / \mathrm{dL}$ ).

After documenting the presence of Whipple's triad in the outpatient setting, the patient underwent an inpatient fast-study. His laboratory evaluation at the onset of hypoglycemia with a BG value of $35 \mathrm{mg} / \mathrm{dL}$ were significant for suppressed levels of C-peptide at $0.2 \mathrm{ng} / \mathrm{mL}$ (normal range: $0.8-3.2 \mathrm{ng} / \mathrm{mL}$ ), low free insulin at $4.5 \mathrm{mU} / \mathrm{L}$ (normal range: 1.0 $24.0 \mathrm{mU} / \mathrm{L}$ ), low proinsulin at $2.3 \mathrm{pmol} / \mathrm{L}$ (normal range: $<8.0 \mathrm{pmol} / \mathrm{L}$ ), suppressed beta-hydroxybutyrate at $<0.10 \mathrm{mmol} / \mathrm{L}$ (normal range: $<0.28 \mathrm{mmol} / \mathrm{L}$ ). On further evaluation he was found to have an IGF-1 level at $158 \mathrm{ng} / \mathrm{mL}$ (normal range: $22-216 \mathrm{ng} / \mathrm{mL}$ ) and an IGF-2 level at $297 \mathrm{ng} / \mathrm{mL}$ (normal range: 333-967 ng/mL). His insulin antibody assay and sulfonylurea drug screens were both negative. Adrenal and thyroid evaluations were unremarkable. Although his IGF-1 level was not suppressed, the rest of his laboratory studies fitted the typical pattern of NICTH. It was concluded at that point that his hypoglycemia was likely mediated by the presence of a tumoral molecule with the capacity of stimulating insulin receptors.

To counteract his hypoglycemia, the patient was scheduled to have frequent high protein and complex carbohydrate containing meals throughout the day. Continuous intravenous dextrose infusions and enteral tube feeds were also added to his regimen. He was also started on prednisone $40 \mathrm{mg}$ daily, which was subsequently increased to 60 mg daily in split doses. Despite these interventions, he continued to

Correspondence to: Vinni Makin, MD FACE, Endocrinology and Metabolism Institute, Cleveland Clinic, 9500 Euclid Avenue /F20, Cleveland, OH 44195, USA, Tel: 216-444-0539; Fax: 216-445-1656; E-mail: makinv@ccf.org

Key words: hypoglycemia, lung adenocarcinoma, non-islet tumor, recombinant human growth hormone

Received: June 25, 2017; Accepted: August 04, 2017; Published: August 17, 2017 
experience frequent recurrences of severe hypoglycemia with BG documented as low as $24 \mathrm{mg} / \mathrm{dL}$ (Figure 1). Given the severity of the hypoglycemic episodes and their detrimental effects on the patient's overall quality of life, it was felt at that point that his case warranted a trial of rhGH therapy, despite the patient being in a "non-palliative" timeframe with regards to his life-expectancy.

Following an informed discussion regarding the risks and benefits of the use of rhGH, the patient elected to start the therapy. Given the high severity and life-threatening nature of his hypoglycemic episodes, he was started on rhGH $3.0 \mathrm{mg}$ once daily. To achieve a better effect the rhGH was increased to $2.0 \mathrm{mg}$ twice daily then to $4.0 \mathrm{mg}$ twice daily, a dose previously reported in the literature [4]. The patient's hypoglycemia significantly improved after initiation of rhGH (Figure 1). The enteral tube feeds and the continuous intravenous dextrose infusions were all discontinued shortly after initiation of rhGH. The prednisone was tapered off within 1 week, and patient was safely discharged home on rhGH only. Thereafter, the patient was able to maintain all BG values above $70 \mathrm{mg} / \mathrm{dL}$.

At a follow up visit, 6 weeks post-rhGH initiation, the patient continued to maintain his BG between 81 and $118 \mathrm{mg} / \mathrm{dL}$. At that time, his tumor staging imaging showed regression of tumor size at primary and distant metastatic sites, as expected with his current oncology regimen. The patient experienced no side effects related to rhGH therapy, even at the high dosages. He continued to do well and has remained on Afatinib therapy with favorable oncological response up-to-date.

\section{Discussion}

NICTH is a rare paraneoplastic phenomenon encountered in the setting of a wide variety of benign and malignant tumors. The majority of cases have been described with mesenchymal tumors and hepatocellular carcinoma, but other reported tumor types include sarcomas, adenocarcinomas, gastrointestinal stromal tumors and renal cell carcinoma [7]. To our knowledge, no other cases of NICTH have been previously described in association with adenocarcinoma of the lung.
In most of the cases, the pathogenesis of NICTH has been related to presence of "big" IGF-2 molecules. These molecules are formed due to abnormal processing of an IGF-2 precursor in tumors with aberrant IGF-2 gene transcription and gene expression $[8,9]$. This disrupts the normal creation of ternary complexes of IGF-2, IGF-binding protein 3 (IGFBP-3), and acid labile subunit (ALS). Consequently, big IGF2 molecules are mainly found within smaller binary complexes and a greater fraction stays in the free form. Both the binary complexes and the unbound big IGF- 2 can cross the capillary membranes and can act on insulin and IGF-1 receptors, ultimately leading to hypoglycemia and suppression of the pituitary GH-IGF-1 axis [10-12].

The typical pattern for NICTH includes low serum glucose level with simultaneous low insulin/proinsulin/C-peptide/betahydroxybutyrate levels, and negative results on an oral hypoglycemic agent screen [7]. The IGF-2 levels may or may not be elevated [13], though have been consistently reported to be higher than the IGF-1 levels. And thus, reported IGF-2:IGF-1 ratios in cases of NICTH have been elevated, in some cases as high as 10:1 [11,14].

Treatment of NICTH should be focused on treating the malignancy itself. If removal is not possible, palliative tumor debulking is likely to decrease the severity of hypoglycemic events [2]. Treatment with chemotherapy and radiation has also proven to be of benefit [7]. When the tumor cannot be excised, other alternative therapies have an integral role in the management of this condition.

As with any episode of hypoglycemia, the immediate goal is to achieve euglycemia. Initially, an increase in enteral intake (whether in amount of food, caloric density, and/or frequency) should be tried in addition to intravenous glucose or dextrose [7]. If nutritional interventions do not suffice, injected glucagon may also be used as a transient measure when hypoglycemic episodes arise. For a more prolonged effect, continuous glucagon infusion has been tried with success in some cases $[15,16]$, but it does not provide a realistic longterm solution for non-palliative patients.

Glucocorticoids are the most extensively described medical therapy for NICTH. They can be useful in treating hypoglycemia via reduction

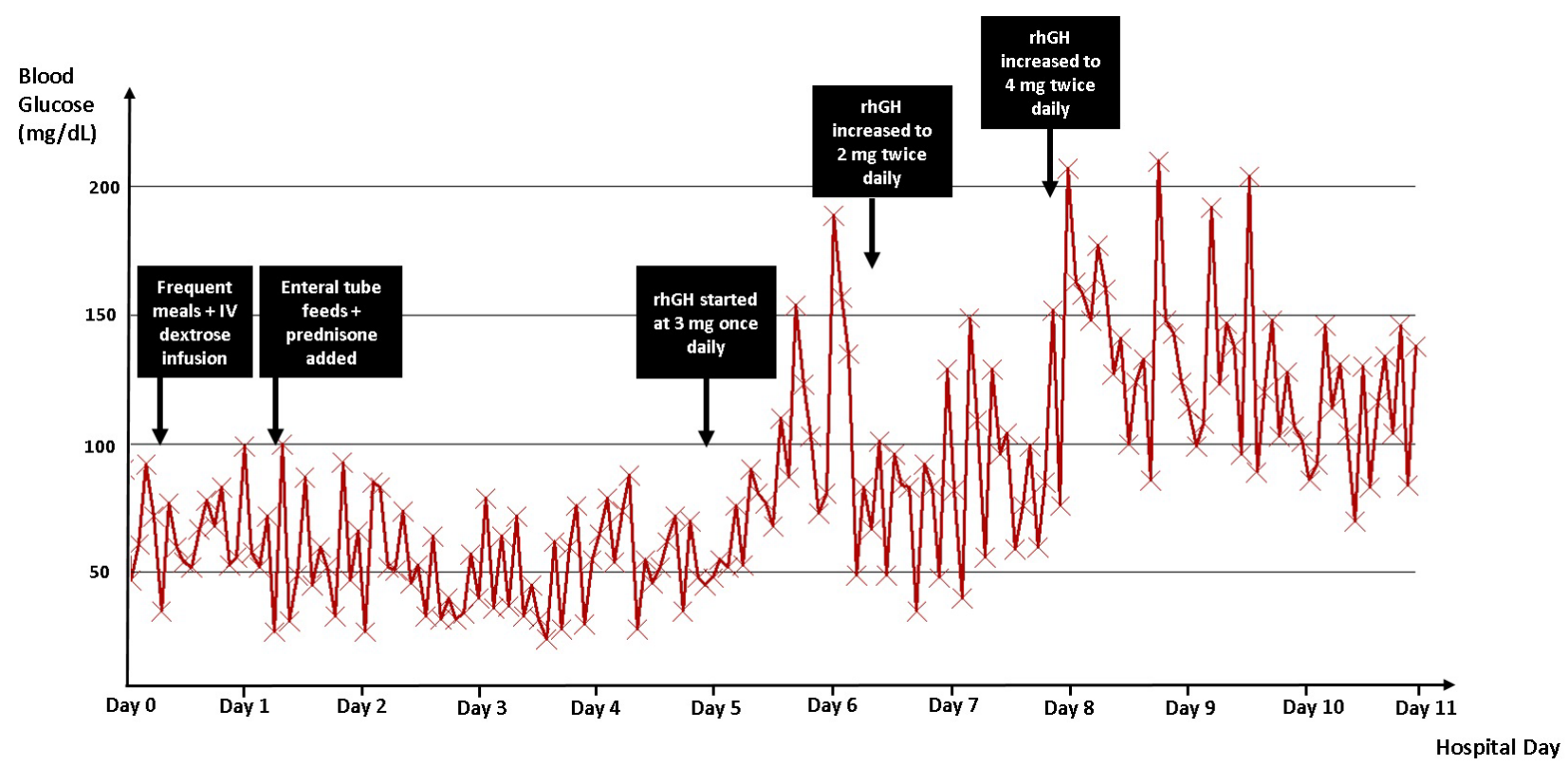

Figure 1. Blood glucose trend throughout patient's hospital stay. rhGH: recombinant human growth hormone. 
in IGF-2 levels [17]. However, several cases have been reported where glucocorticoids failed to treat NICTH, even with extremely high doses $[18,19]$. In a refractory setting, as was shown in this case, rhGH can be considered as well. GH suppresses peripheral glucose uptake [3] and leads to increased levels of IGF-1, IGFBP-3, and ALS, with resultant promotion of the normal ternary-complexed IGF-2 $[13,17,20]$. Drake et. al. reported the use of rhGH in two patients with pleural masses who both continued to experience hypoglycemia despite several attempted treatments. Both patients improved when treatment with rhGH was initiated [4]. The glucose levels stabilized on 6 and $8 \mathrm{mg}$ daily of rhGH daily [4]. Others reported the use of up to $12 \mathrm{mg}$ of rhGH daily for treatment of malignancy-induced hypoglycemia [5]. It should be noted that use of rhGH should reduce the need for other therapies, such glucocorticoid therapy, the latter of which puts patients at a high risk for pathologic fractures, especially in the setting of concomitant bone metastases.

The current literature and experts' recommendations for the use of rhGH implicate the use of the latter for palliation purposes in NICTH. The case presented here raises questions regarding the definition of "palliation" in this context. We believe it ought to be based on a measure of quality of life rather than the conventional " 6 months or less" outlook. More importantly, such treatment should always be discussed with patients, in the context of shared medical decisionmaking, for the therapy to be aligned with their wishes and values.

\section{Conclusion}

We demonstrated the successful use of rhGH as a therapy outside of the conventional palliative care setting, in treating a case of severe, refractory NICTH.

\section{Disclosure statement}

The authors declare that there is no conflict of interest or funding received regarding the publication of this paper.

\section{References}

1. Scott K (2009) Non-islet cell tumor hypoglycemia. J Pain Symptom Manage 7: 1-3. [Crossref]

2. Dynkevich Y (2013) Tumors, IGF-2, and hypoglycemia: insights from the clinic, the laboratory, and the historical archive. Endocr Rev 34: 798-826. [Crossref]

3. Bourcigaux N (2005) Treatment of hypoglycemia using combined glucocorticoid and recombinant human growth hormone in a patient with a metastatic non-islet cell tumor hypoglycemia. Clin Ther 27: 246-251. [Crossref]
4. Drake WM (1998) Dose-related effects of growth hormone on IGF-I and IGF-binding protein-3 levels in non-islet cell tumour hypoglycaemia. Eur J Endocrinol 139: 532536. [Crossref]

5. Krishnan L, Clark J (2011) Non-islet cell tumour hypoglycaemia. BMJ Case Rep.

6. Iglesias P, Diez JJ (2014) Management of endocrine disease: a clinical update on tumor-induced hypoglycemia. Eur J Endocrinol 170: 147-157. [Crossref]

7. Bodnar TW, Acevedo MJ, Pietropaolo M (2014) Management of non-islet-cell tumor hypoglycemia: a clinical review. J Clin Endocrinol Metab 99: 713-722. [Crossref]

8. Bertherat J, Logié A, Gicquel C, Mourriéras F, Luton JP, et al. (2000) Alterations of the $11 \mathrm{p} 15$ imprinted region and the IGFs system in a case of recurrent non-islet-cell tumour hypoglycaemia (NICTH). Clin Endocrinol (Oxf) 53: 213-220. [Crossref]

9. Tani Y, Tateno T, Izumiyama H, Doi M, Yoshimoto T, et al. (2008) Defective expression of prohormone convertase 4 and enhanced expression of insulin-like growth factor II by pleural solitary fibrous tumor causing hypoglycemia. Endocr $J$ 55: $905-$ 911. [Crossref]

10. De Groot JW, Rikhof B, van Doorn J (2007) Non-islet cell tumour-induced hypoglycaemia: a review of the literature including two new cases. Endocr Relat Cancer 14: 979-993. [Crossref]

11. Fukuda I, Hizuka N, Ishikawa Y (2006) Clinical features of insulin-like growth factorII producing non-islet-cell tumor hypoglycemia. Growth Horm IGF Res 16: 211-216. [Crossref]

12. Thomas J, Kumar S (2013) Nonislet Cell Tumor Hypoglycemia. Case Rep Endocrinol 30: 80-86. [Crossref]

13. Baxter RC (1996) The role of insulin-like growth factors and their binding proteins in tumor hypoglycemia. Horm Res 46:195-201. [Crossref]

14. Teale JD (1999) Non-islet cell tumour hypoglycaemia. Clin Endocrinol (Oxf) 51: 147 150

15. Rastogi MV, Desai N, Quintos JB (2008) Non-islet-cell tumor hypoglycemia and lactic acidosis in a child with congenital HIV and Burkitt's lymphoma. J Pediatr Endocrinol Metab 21: 805-810. [Crossref]

16. Hoff AO, Vassilopoulou-Sellin R (1998) The role of glucagon administration in the diagnosis and treatment of patients with tumor hypoglycemia. Cancer 82:15851592. [Crossref]

17. Baxter RC, Holman SR, Corbould A (1995) Regulation of the insulin-like growth factors and their binding proteins by glucocorticoid and growth hormone in non-islet cell tumor hypoglycemia. J Clin Endocrinol Metab 80: 2700-2708.

18. Mukherjee S, Diver M, Weston PJ (2005) Non-islet cell tumor hypoglycaemia in a metastatic Leydig cell tumor. Acta Oncol 44: 761-763. [Crossref]

19. Powter L, Phillips S, Husbands E (2013) A case report of non-islet cell tumour hypoglycaemia associated with ovarian germ-cell tumour. Palliat Med 27: 281-283.

20. Teale JD, Blum WF, Marks V (1992) Alleviation of non-islet cell tumour hypoglycaemia by growth hormone therapy is associated with changes in IGF binding protein-3. Ann Clin Biochem 29: 1-10. [Crossref]

Copyright: (C2017 Ca A. This is an open-access article distributed under the terms of the Creative Commons Attribution License, which permits unrestricted use, distribution, and reproduction in any medium, provided the original author and source are credited. 